\title{
Happiness, Hope, and Affection as Predictors of Quality of Life and Functionality of Individuals With Heart Failure at Three-Month Follow-up
}

\author{
Elisabete Diogo Proença \\ Nave-Leal \\ Lisbon Polytechnic Institute, \\ Lisbon, Portugal
}

\author{
José Luis Pais-Ribeiro \\ Porto University, \\ Porto, Portugal
}

\author{
Mário João Martins-Oliveira \\ Lisbon's Central Hospital Center, \\ Lisbon, Portugal
}

\begin{abstract}
The scientific evidence supporting the management of the chronically ill in a positive psychological perspective in opposition to traditional pathological approach is scarce. This study examines issues associated with recovery of health status in heart failure, in particular hope, affection, and happiness. We use a longitudinal study of 128 symptomatic patients who after medical intervention reported improved quality of life and function at 3-month follow-up. We evaluated the contribution of happiness, hope and affection, individually and as a whole, in the quality of life and functionality of individuals with heart failure. Happiness (Subjective Happiness Scale), Hope (HOPE Scale), and affection (PANAS (positive and negative affect schedule)) were determined before medical intervention. Individually, we found that happiness is correlated with the quality of life and functionality, hope to self-efficacy dimension of the quality of life scale, positive affect to functionality and negative affect with symptoms dimension, quality of life dimension, and overall sum of the quality of life scale. Overall, we found that happiness has a unique contribution to the quality of life, except in self-efficacy dimension where hope takes this contribution and positive affect has a unique contribution to the functionality in this short-term follow-up. The results highlight the importance of positive variables to health outcomes for people with heart failure and should be considered in intervention programs for this syndrome.
\end{abstract}

Keywords: happiness, hope, affection, quality of life, functionality, heart failure

\section{Introduction}

The increase in life expectancy recorded in the Western populations and the extend of life that the therapeutic advances of recent years offer to patients with heart failure are responsible for the increased incidence and prevalence of this syndrome and lead us to predict that it will be one of the most common cardiovascular diseases. Currently, it is already considered a real public health problem. During the establishment of clinical stage, chronic heart failure is a situation with high mortality and morbidity, disability, repeated hospitalizations, and generating huge expenses (Cândida, 1999).

In the last decades, we assisted the emergence of innovative medical interventions, such as cardiac

Elisabete Diogo Proença Nave-Leal, Ph.D., professor, School of Health Technology of Lisbon, Lisbon Polytechnic Institute. José Luis Pais-Ribeiro, Ph.D., professor, Faculty of Psychology and Educational Sciences, Porto University.

Mário João Martins-Oliveira, Ph.D., professor, Santa Marta's Hospital, Lisbon's Central Hospital Center. 
resynchronization and heart transplantation, now widely implemented strategies that have provided a reduction in mortality and morbidity as well as an improved quality of life of these people affected in their functionality in its various strands (Cleland et al., 2005; White-Williams, Jalowiec, \& Grady, 2005).

Along with the medical interventions, we know that the individual characteristics of patients are essential to health outcomes. If the negative aspects, such as negative affect, are clearly associated with increased morbidity and mortality and poor quality of life (Doering et al., 2004; Moser, 2002), this relationship when referring to the positive aspects is still unclear.

Research shows the positive affect associated with decreased morbidity and symptomatology (Pressman \& Cohen, 2005) and report their ability to reverse the consequences of experiencing stressful events by stopping or reducing their impact on the cardiovascular system and thereby being protective of health (Fredrikson, 1998).

Hope is associated to quality of life and mental health in the cardiac patient in the sense that a low level of hope is linked to poor quality of life and psychiatric disorders (Evangelista, Doering, Dracup, Vassilakis, \& Kobashigawa, 2005).

Several authors reported that happy people identify better health and less unpleasant physical symptoms (Kehn, 1995; Mroczeck \& Spyro, 2005; Roysamb, Tambs, Reichborn-Kjennerud, Neale, \& Harris, 2003).

These promising studies boost research in the field of cardiology in general and heart failure in particular to clarify the relationship of personality characteristics, including positive ones, to target interventions to improve individual functioning and well-being, and to increase control about physical health, with positive results in the quality of life and in the results of therapeutic interventions that they are submitted to.

Thus, we intend to evaluate the contribution of happiness, hope, and affection, individually and as a whole, in the quality of life and functionality of individuals with heart failure.

\section{Method}

\section{Participants}

A total of 128 individuals, 98 men and 30 women diagnosed with heart failure admitted to Santa Marta's Hospital in the services of cardiology and cardiothoracic surgery, constituted a convenience sample aged $61.9 \pm$ 12.1 years old, with $6.6 \pm 3.9$ years of education and $74.2 \%$ retired due to this syndrome, $56.3 \%$ were in class III New York Heart Association with poor ejection fraction of left ventricle $(25.3 \% \pm 6.2 \%)$, having a history of $9.4 \pm 8.5$ years for heart failure, with at least one hospitalization due to this syndrome and the majority of ischemic etiology (51.6\%) (see Table 1).

\section{Material}

We evaluated happiness with the Subjective Happiness Scale developed by Lyubomirsky and Lepper (1999) and translated into Portuguese language by Bertoquini and Pais-Ribeiro (2004). It consists of four items in which the first two items request the subject to characterize his/her happiness using absolute and relative ratios in relation to his/her pairs, while the other two items offer descriptions of happy and unhappy individuals. The subject is asked to identify at a 7-point ordinal scale, the point at which that characterization better describes him/her, where a higher rate indicates higher levels of happiness.

Hope was evaluated by the Hope (HOPE Scale) developed by Snyder et al. (1991) and validated for the Portuguese population by Pais-Ribeiro, Pedro, and Marques (2006). It consists of 12 items (shown as a 
statement), eight assess hope plus four distractors. Of the eight items that assess hope, four items assessing the initiative, past, present, and future, plus four items that assess the ways. Subjects are asked to read each statement and respond how he/she apply to them, at an 8-point ordinal scale from "Completely false (= 1)" to "Completely true $(=8)$ ", where a higher rate indicates a higher level of hope.

Table 1

Characteristics of the Sample

\begin{tabular}{|c|c|c|c|c|c|}
\hline & & $\%$ & $M$ & $S D$ & Range \\
\hline \multirow{2}{*}{ Sex } & Male & 76.6 & & & \\
\hline & Female & 32.4 & & & \\
\hline Age & & & 61.83 & 12.07 & $21-85$ \\
\hline Education & & & 6.64 & 3.93 & $0-17$ \\
\hline \multirow{3}{*}{ Profession } & Active & 21.1 & & & \\
\hline & Retired & 74.2 & & & \\
\hline & Not working & 4.7 & & & \\
\hline Years of diagnosis & & & 9.4 & 8.5 & $1-40$ \\
\hline \multirow{4}{*}{ Etiology } & Ischemic & 51.6 & & & \\
\hline & Hipertensive & 3.1 & & & \\
\hline & Valvular & 10.9 & & & \\
\hline & Idiopathic & 34.4 & & & \\
\hline Left ventricle ejection fraction & & & 25.8 & 6.21 & $11-35$ \\
\hline \multirow{4}{*}{$\begin{array}{l}\text { New York Heart Association } \\
\text { Classification }\end{array}$} & I & 0 & & & \\
\hline & II & 32.8 & & & \\
\hline & III & 56.3 & & & \\
\hline & IV & 10.9 & & & \\
\hline
\end{tabular}

The affection was measured by the PANAS (Positive and Negative Affect Schedule) developed by Watson, Clark, and Tellegen (1988) and validated for the Portuguese population by Galinha and Pais-Ribeiro (2005a; 2005b). It consists of 10 items for positive affect (enthusiastic, delighted, inspired, excited, determined, pleasantly surprised, warm, active, interested, and proud) and 10 items for negative affect (disturbed, troubled, frightened, scared, angry, nervous, trembling, guilt, repulse, and remorse). The subject is asked to say how much affection he/she felt last week in a 5-point ordinal scale from "No or very slightly (=1)" to "Extremely (= 5)", where a higher rate indicates higher levels of positive affect and negative affect.

The health outcomes were evaluated by the quality of life assessed by the KCCQ (Kansas City Cardiomyopathy Questionnaire) developed by Green, Porter, Bresnahan, and Spertus (2000) and validated for the Portuguese population by Nave-Leal et al. (2010). It consists of 23 items distributed across five domains: physical limitation, symptoms (frequency, severity, and stability of symptoms), quality of life, self-efficacy, and social limitation. The field of physical limitation measure to what extent the symptoms of heart failure have limited some daily activities of the patients within two weeks. The symptoms domain measures the number of times that the heart failure symptoms, such as fatigue, shortness of breath, or swelling of the extremities occurred within two weeks, and if these symptoms changed in that time period. The self-efficacy domain measures the patient's ability to understand how to avoid the worsening of symptoms and what to do if this occurs. The quality of life domain assesses the patient's perception about his/her enjoyment in living or 
discouragement because of their heart disease. The social limitation domain assesses how heart failure affects the lifestyle of patients. To facilitate interpretation of results, the authors constructed two sums: The first called functional status, which includes the areas of physical limitations and symptoms, excluding the question of the stability of symptoms; and the second, global called clinical summary, which includes the sum of functional status, quality of life, and social limitation domains. The results of the scales are transformed to $0-100$ by subtracting the lower value domain, followed by division by the highest value minus the lowest and multiplying by 100 , where higher scores indicate better health status. The subjects were asked to answer the 15 questions in Likert scales of 5-, 6-, or 7- point.

Functionality was assessed by New York Heart Association Classification, and for one question related to the practice of physical exercise. The classification of the New York Heart Association developed by the Criteria Committee of the New York Heart Association in 1964 measures the functional capacity based on the severity of symptoms and limitation of physical activity and is the most widely used measure for evaluating the functionality of the cardiac patient. Class I is defined by the absence of limitations where the usual physical activity does not cause fatigue, dyspnoea, or inadequate palpitations; Class II is characterized by a slight limitation of physical activity, comfortable at rest but the usual physical activity causes fatigue, palpitations, or dyspnoea; Class III is defined by a marked limitation of physical activity, comfortable at rest but a less intense activity than the usual causes heart failure symptoms; and Class IV is characterized by an inability to perform any physical activity without discomfort, where the symptoms of heart failure are present even at rest, and this discomfort increases with any physical activity. As the subjects have more severe symptoms and greater limitation of physical activity (as we move from Class I - the most functional to Class IV— the less functional), the prognosis worsens, with a lower class corresponding to more functionality. We built three items to classify physical activity according to the recommendations of Briffa et al. (2006) for physical exercise in heart failure considering as regular the performance of any physical activity that enhances or maintains physical fitness and health with a periodicity of at least three times weekly and at least 30 minutes each day, rarely the practice of physical exercise less than this and never if currently does not perform any physical activity to maintain their physical condition.

\section{Procedure}

These patients underwent medical therapy: cardiac resynchronization therapy $(N=52)$, implantable cardioverter-defibrillator $(N=44)$, valve surgery with coronary artery bypass graft surgery $(N=14)$, optimizing drug therapy $(N=10)$, and heart transplantation $(N=8)$ (see Table 2). We evaluated before the medical therapy regarding the quality of life, functionality, happiness, hope, and affection, and at three months after the medical intervention on the quality of life and functionality.

Table 2

Medical Therapy Received by the Sample

\begin{tabular}{lcc}
\hline Medical therapy & $N$ & Percentage (\%) \\
\hline Heart transplantation & 8 & 6.3 \\
Implantable cardioverter-defibrillator & 44 & 34.4 \\
Cardiac resynchronization therapy & 52 & 40.6 \\
Valve surgery with coronary artery bypass graft surgery & 14 & 10.4 \\
Optimizing drug therapy & 10 & 7.8 \\
\hline
\end{tabular}




\section{Results}

At three months after medical therapy, eight people died (three underwent heart transplantation, three submitted to implantable cardioverter-defibrillator, one submitted to cardiac resynchronization therapy, and one received optimal drug therapy), in the 120 individuals evaluated three months after therapy, we found that ejection fraction of left ventricle increased to $30.8 \% \pm 10.1 \%$, with $74.8 \%$ in Class II of the New York Heart Association Classification (see Table 3). The functionality and quality of life increased in all domains and sums $(\rho<0.05)$.

Table 3

Characteristics of the Sample at Three-Month Follow-up

\begin{tabular}{llllll}
\hline & & Percentage (\%) & $M$ & $S D$ & Range \\
\hline Left ventricle ejection fraction & & & 30.8 & 10.1 & $13-61$ \\
\hline \multirow{2}{*}{ New York Heart Association Classification } & I & 12.6 & & \\
& II & 74.8 & & \\
& III & 12.6 & & \\
\hline
\end{tabular}

Evaluating individually the influence of happiness, hope, and affection in the quality of life and functionality reported at three months after the medical intervention, we found that happiness was positively correlated with quality of life (with the exception of the self-efficacy dimension), the positive affect with functionality (with the exception of the New York Heart Association Classification) and the negative affect were negatively correlated with the quality of life (except for physical limitation dimension, self-efficacy domains, and functional status) $(\rho<0.05)$ (see Table 4).

Table 4

Correlations Between Happiness, Hope, Affection and the Quality of Life and Functionality at Three-Month Follow-up

\begin{tabular}{llllc}
\hline & SHS & HOPE global & \multicolumn{2}{c}{ PANAS } \\
\cline { 5 - 5 } & & & Positive affect & Negative affect \\
\hline KCCQ & & & & -0.15 \\
Physical limitation & $0.28^{* *}$ & 0.01 & -0.06 & $-0.20^{*}$ \\
Symptoms & $0.25^{* *}$ & -0.01 & -0.12 & 0.08 \\
Self-efficacy & 0.12 & $-0.22^{*}$ & 0.01 & $-0.29^{* *}$ \\
Quality of life & $0.39^{* *}$ & 0.05 & 0.11 & $-0.23^{*}$ \\
Social limitation & $0.29^{* *}$ & 0.16 & 0.15 & -0.17 \\
Functional status & $0.27^{* *}$ & -0.01 & 0.10 & $-0.21^{*}$ \\
Clinical summary & $0.31^{* *}$ & 0.04 & 0.12 & 0.03 \\
New York Heart Association Classification & $-0.19^{*}$ & 0.12 & -0.14 & 0.10 \\
Physical exercise & $-0.19^{*}$ & 0.01 & $-0.26^{* *}$ & \\
\hline
\end{tabular}

Notes. ${ }^{*} p<0.05 ;{ }^{* *} p<0.01$; KCCQ: questionnaire of quality of life in heart failure; SHS: happiness scale; HOPE: hope scale; PANAS: affection scale.

Following the tendency of the individual contribution of these variables, we evaluated these variables together by linear regression analysis and found happiness as a unique contribution to the quality of life, with a contribution of $R_{(\text {adj) }}^{2}=0.06$ for physical limitation dimension $(\beta=0.28, \rho<0.05)$, a contribution of $R_{(\text {adj })}^{2}=0.06$ for symptoms dimension $(\beta=0.20, \rho<0.05)$, a contribution $R_{(\mathrm{adj})}^{2}=0.09$ for social limitation dimension $(\beta=$ 
$0.22, \rho<0.05)$, a contribution of $R_{(\text {adj) }}^{2}=0.06$ for the sum functional status $(\beta=0.24, \rho<0.05)$, and a contribution of $R^{2}{ }_{(\mathrm{adj})}=0.09$ for the sum clinical summary $(\beta=0.27, \rho<0.05)$. Hope has a unique contribution to the self-efficacy dimension of the quality of life scale, with a contribution of $R_{(\text {adj })}^{2}=0.03$ for self-efficacy ( $\beta$ $=0.23, \rho<0.05$ ). Happiness and negative affect have a unique contribution to the quality of life dimension of quality of life scale, with a contribution of $R^{2}{ }_{(\mathrm{adj})}=0.17$ for the dimension quality of life $(\beta=-0.22, \beta=0.36, \rho$ $<0.05$, negative affect and happiness respectively). It was found that positive affect has a unique contribution to the functionality with a contribution of $R_{(\text {(adj) }}^{2}=0.07$ for physical exercise $(\beta=-0.26, \rho<0.05)$. To the New York Heart Association Classification, there was a contribution of $R_{(\text {adj })}^{2}=0.05$ with the variables sharing the variance between them.

\section{Discussion}

In this study, happiness emerges as a predictor of quality of life, sharing this contribution with the negative affect on the quality of life dimension. Hope emerges as a predictor of self-efficacy dimension of the quality of life scale. The positive affect arises as a predictor of functionality considering the practice of physical exercise.

Recently, these variables are being studied in health in general, in cardiology patients and heart failure in particular. For instance, in studies centred in hope, Evangelista et al. (2005) in their study with women undergoing cardiac transplantation verified the existence of low levels of hope and high levels of anxiety, depression, and hostility, and hope was identified as a predictor of mood states and quality of life. Rustoen, Howie, Eidsmo, and Moum (2005) in a study of 93 patients with heart failure compared with 441 individuals, found that after controlling for demographic variables, patients with heart failure had higher levels of hope than the control group, according to these authors due to adaptation to chronic illness. Patients with skin problems and psychiatric disorders showed lower levels of hope, identifying these two comorbidities as predictors of hope.

There is many research regarding the influence of negative affect on health outcomes and can be found several investigations with people with heart failure. Steptoe, Mohabir, Mahon, and McKenna (2000) in a study in patients with dilated cardiomyopathy, reported high levels of anxiety and depression; Trigo, Silva, and Rocha (2005) in a review study identified depression and vital exhaustion as independent risk factors in incidence and prognosis of coronary disease; Lee, Yu, Woo, and Thompson (2005) found a relation between psychological distress and poor quality of life. The prognostic value is undeniable. Depression is found as a factor predictive of rehospitalization and mortality in chronic heart failure in several studies (Faris, Purcel, Henein, \& Coats, 2002, Jiang et al., 2004; Moser, 2002).

Studies that establish the relationship between positive affects on health are scarce. Pressman and Cohen (2005) in a review article, identified an association between high levels of positive affect and health, reporting that trait positive affect (stable disposition) is associated with decreased morbidity and state positive affect (short positive affect) is related with decreased symptoms and pain. These authors found in prospective studies of morbidity benefits of positive affect trait in conditions as diverse as stroke, rehospitalization due to coronary heart disease, flu, and accidents. In survival studies, they found little consistency. However, it identified a pattern that indicates that people in terminal stages of illness and disease with high mortality rates and upcoming (patients with melanoma), are hampered by high positive affect, whereas other diseases with the highest expectations of survival, where adherence to treatment and other behaviours (exercise and sleep) are fundamental, benefit from the positive affect or are not affected. For the cardiovascular system, these authors 
stated that positive affect may contribute to health in that it is associated with changes in baseline levels of cardiovascular response. Changes in positive affect state and acute changes in cardiovascular response may be important for those with chronic conditions where short-term emotions can trigger an event, such as an asthma attack or acute myocardial infarction. Generally, low levels of stimulation of the cardiovascular response are assumed as health promoters, while high levels of stimulation of the cardiovascular response have the potential to pose a risk to health, but to a lesser extent that negative emotions such as anger (Pressman \& Cohen, 2005). Lyubormisky, King, and Diener (2005) reported that individuals with high trait positive affect, are less likely to suffer from depression. Fredrickson (1998) in a review article referred to the capacity of positive affect to reverse the consequences of experiencing negative emotions, interrupting or reducing the impact that stress has in the cardiovascular system, and thereby protecting health.

The effect of happiness on health has been investigated. It is believed that happiness aids healing and protects against disease. Veenhoven (2009) in a review of the literature suggested that happiness does not cure serious diseases, but protects us from getting sick. This author concluded that happy people have greater longevity, probably because happiness protects health, alerting to the fact that public health could benefit from the promotion of happiness. Several authors state that happy people report better health and less unpleasant physical symptoms (Kehn, 1995; Mroczeck \& Spyro, 2005; Roysamb, Tambs, Reichborn-Kjennerud, Neale, \& Harris, 2003). Diener and Seligman (2002) found that the happiest people showed less psychopathological symptoms like depression, hypochondriasis, or schizophrenia. Middleton and Byrd (1996) found that in a group of 121 cardiovascular patients who were previously hospitalized due to his/her heart problem, happiness predicts rehospitalization (after controlling for other chronic diseases, length of hospitalization, perceived health and hope for the future), reinforcing the importance of this variable in the study of these patients. A study in the United Kingdom quite significantly contributed to demonstrate that the level of happiness experienced by the cardiac patient can have a positive impact on their health. In this study, which involved 216 individuals of middle age and both sexes, patients who were happy had the blood levels of cortisol (high levels of cortisol are usually related to the development of type II diabetes and hypertension) smaller in $32 \%$ than those who reported being unhappy. The authors stated that a positive mental state, either on a daily basis or before adverse situations, may affect cortisol levels, fibrinogen, blood pressure and heart rate, reinforcing the idea that happiness and health have a very strong bond (Steptoe, Wardle, \& Marmot, 2005).

Research relating to these promising variables starts taking the first steps, indicating an urgent need for more studies covering the positive psychology and its applicability to health. However, one begins to highlight the importance of these positive variables to health outcomes for people with heart failure. Thus, we suggest that should be taken into account in intervention programs for people with heart failure.

\section{References}

Bertoquini, V., \& Pais-Ribeiro, L. (2004). Escala de felicidade subjectiva (available from V. Bertoquini, bertoquini@gmail.com)

Briffa, T., Maiorana, A., Sheerin, N., Stubbs, A., Oldenburg, B., Sammel, N., \& Allan, R. (2006). Physical activity for people with cardiovascular disease: Recommendations of the national heart foundation of Australia. Medical Journal of Australia, 184(2), 71-75.

Cândida, F. (1999). Prévalence de l'insuffisance Cardiaque au Portugal. Revista Portuguesa de Cardiologia, 18, 1151-1155.

Cleland, J. G. F., Daubert, J. C., Erdmann, E., Freemantle, N., Gras, D., Kappenberger, L., \& Tavazzi, L. (2005). The effect of cardiac resynchronization on morbidity and mortality in heart failure. The New England Journal of Medicine, 352, $1539-1549$.

Diener, E., \& Seligman, M. (2002).Very happy people. Psychological Science, 13, 81-84. 
Doering, L.V., Dracup, K., Caldwell, M. A., Moser, D. K., Erickson, V. S., Fonarow, G., \& Hamilton, M. (2004). Is coping style linked with emotional states in heart failure patients? Journal of Cardiac Failure, 10(4), 344-349.

Evangelista, L. S., Doering, L. V., Dracup, K., Vassilakis, M. E., \& Kobashigawa, J. (2003). Hope, mood states and quality of life in female heart transplant recipients. The Journal of Heart and Lung Transplantation, 22(6), 681-686.

Faris, R., Purcell, H., Henein, M., \& Coats, A. (2002). ESC guidelines for the diagnosis and treatment of acute and chronic heart failure. The European Journal of Heart Failure, 4, 541-551.

Fredrickson, B. (1998). What good are positive emotions? Review of General Psychology, 2(3), 300-319.

Galinha, I. C., \& Pais-Ribeiro, J. L. (2005a). Contribuição para o estudo da versão portuguesa da positive and negative affect schedule (PANAS): I-Abordagem teórica ao conceito do afecto. Análise Psicológica, 2 (XXIII), 209-218.

Galinha, I. C., \& Pais-Ribeiro, J. L. (2005b). Contribuição para o estudo da versão portuguesa da positive and negative affect schedule (PANAS): II-Estudo psicométrico. Análise Psicológica, 2(XXIII), 219-227.

Green, C. P., Porter, C. B., Bresnahan, D. R., \& Spertus, J. A. (2000). Development and evaluation of the Kansas City cardiomyopathy questionnaire: A new health status measure for heart failure. Journal of the American College of Cardiology, 5(35), 1245-1255.

Jiang, W., Kuchibhatla, M., Cuffe, M., Christopher, E., Alexander, J., Clary, G., ..., \& O'Connor, C. (2004). Prognostic value of anxiety and depression in patients with chronic hear failure. Circulation, 110, 3452-3456.

Kehn, D. J. (1995). Predictors of elderly happiness. Activities, Adaptation and Aging, 19, 11-30.

Lee, D., Yu, D., Woob, J., \& Thompson, D. (2005). Health-related quality of life in patients with congestive heart failure. The European Journal of Heart Failure, 7, 419-422.

Lyubomirsky, S., \& Lepper, H. S. (1999). A measure of subjective happiness: Preliminary reliability and construct validation. Social Indicators Research, 46, 137-155.

Lyubomirsky, S., King, L., \& Diener, E. (2005). The benefits of frequent positive affect: Does happiness lead to success? Psychologiacal Bulletin, 131(6), 803-855.

Middleton, R., \& Bird, E. (1996). Psychosocial factors and hospital readmission status of older persons with cardiovascular disease. Journal of Applied Rehabilitation Counseling, 27(4), 3-10.

Moser, D. K. (2002). Psychosocial factors and their association with clinical outcomes in patients with heart failure: Why clinicians do not seem to care. European Journal of Cardiovascular Nursing, 1, 183-188.

Mroczeck, D. K., \& Spiro, A. (2005). Change in life satisfaction during adulthood: Findings from the veterans affairs normative aging study. Journal of Personality and Social Psychology, 88, 189-202.

Nave Leal, E., Pais-Ribeiro, J., Oliveira, M., Nogueira da Silva, J., Soares, R., Fragata, J., \& Ferreira, R. (2010). Propriedades psicométricas da versão portuguesa do Kansas City cardiomyopathy questionnaire na miocardiopatia dilatada com insuficiência cardíaca congestiva. Revista Portuguesa de Cardiologia, 29 (3), 353-372.

Pais-Ribeiro, J., Pedro, L., \& Marques, S. (2006). Contribuição para o estudo psicométrico e estrutural da escala de esperança (de futuro). In I. Leal, J. P. Ribeiro, \& S. N. Jesus (Eds.), Actas do $6^{\circ}$ Congresso Nacional de Psicologia da Saúde (pp. 75-81). Lisboa: Instituto Superior de Psicologia Aplicada.

Pressman, S. D., \& Cohen, S. (2005). Does positive affect influence health? Psychological Bulletin, 131(6), 925-971.

Roysamb, E., Tambs, K., Reichborn-Kjennerud, T., Neale, M. C., \& Harris, J. R. (2003). Happiness and health: Environmental and genetic contributions to the relationship between subjective well-being, perceived health and somatic illness. Journal of Personality and Social Psychology, 85, 1136-1146.

Rustoen, T., Howie, J., Eidsmo, I., \& Moum, T. (2005). Hope in patients hospitalized with heart failure. American Journal of Critical Care, 14, 417-425.

Snyder, C. R., Harris, C., Anderson, J. R., Holleran, S. A., Irving, L. M., \& Sigmon et al. (1991). The will and the ways: Development and validation of an individual-differences measure of hope. Journal of Personality and Social Psychology, 60(4), 570-585.

Watson, D., Clark, L. A., \& Tellegen, A. (1988). Development and validation of brief measures of positive and negative affect: The PANAS scales. Journal of Personality and Social Psychology, 54(6), 1063-1070.

White-Williams, C., Jalowiec, A., \& Grady, K. (2005). Who returns to work after heart transplantation? The Journal of Heart and Lung Transplantation, 24(12), 2255-2261. 